\title{
Dry Matter Requirement for Growth and Respiration of Coconut
}

\author{
C S Ranasinghe and R D N Premasiri \\ Plant Physiology Division, Coconut Research Institute, Lunuwila, Sri Lanka \\ sanathanie_ranasinghe@yahoo.com
}

\begin{abstract}
The present study determined the dry matter (DM) requirement for potential growth (PGR), growth respiration $\left(R_{g}\right)$ and maintenance respiration $\left(R_{m}\right)$ of fruits, leaves, stem and root system of adult coconut palms (25-26 years) of Tall $x$ Tall cultivar under resource-unlimiting conditions. The total DM requirement of a palm was about $21 \mathrm{~kg} / \mathrm{palm} / \mathrm{month}$ and $63 \%$ of that total was required for growth and respiration of vegetative organs (leaves, stem and roots) whilst the rest (37\%) was for fruits. Similarly, the DM required for respiration (62\%) was nearly two third of the total requirement of a palm and the balance $38 \%$ was required for growth of organs. The total dry matter requirement (TDMR) of individual fruits varied with developing stage and TDMR of fruits / palm varied between months and years depending on the fruit load of different development stages. Irrespective of the year, TDMR of fruits was highest during November to February (about $10-11 \mathrm{~kg} / \mathrm{palm} / \mathrm{month}$ ) and lowest in June-July (about $5-6 \mathrm{~kg} / \mathrm{palm} / \mathrm{month}$ ). However, the DM requirement of vegetative organs (a total of approximately $13 \mathrm{~kg} / \mathrm{palm} / \mathrm{month}$ ) did not vary between months.
\end{abstract}

Key words: fruit respiration, fruit growth, Cocos nucifera, assimilate requirement

\section{INTRODUCTION}

Crop yield in tree fruit crops like coconut depends on fruit set and the ability of the tree to supply photosynthates to sustain the growth and respiration requirements of developing fruits. Because of this relationship to crop yield, there has been some research on the factors controlling fruit set and photosynthesis in coconut (Nainanayake et al. 2008; Ranasinghe et al. 2012). But, even though fruits are widely recognized as major 'sinks' for photo-assimilates and the competition for assimilates among fruits is one of the major factors controlling fruit set (Navarro et al, 2008; Ranasinghe et al. 2012), there have been no attempts to quantify actual assimilate requirement for growth and respiration of fruits and other vegetative organs of coconut palms. Furthermore, quantitative information on assimilate requirement (sink strength) of different organs and its interaction with critical climatic factors is necessary for developing source/sink based crop forecasting models.

Coconut palm shows an indeterminate growth pattern, producing an inflorescence 
at each leaf axil at intervals varying from 25 to 30 days, depending on the environmental conditions and age of the palm (Liyanage, 1950). Consequently, at any time a healthy coconut palm carries 12-14 inflorescences (bunches) with varying numbers of fruits at different developing stages. Thus, the total assimilate (dry matter) requirement of a coconut palm is the dry matter required for potential growth and respiration of vegetative and reproductive organs. The supply of assimilates, originating from the photosynthesis, is divided over the organs in proportion to their fractional contribution to the total sink strength (Bertin, 1995; Marcelis, 1996). In a perennial crop like coconut with simultaneous growth of vegetative and reproductive organs, the dry matter requirement of vegetative organs has the priority over fruits (Navarro et al. 2008) and therefore, when the total dry matter requirement of the palm is high, flowers and young fruits are not able to compete for assimilates with the fast-growing fruits and hence abort resulting low fruit set.

The dry matter requirement for 'potential growth' of fruits and vegetative organs can be estimated by determining the growth rate of these organs under resource "nonlimiting' conditions, i.e. with no soil moisture stress, no nutrient deficiency, at favorable temperature and solar radiation intensity and with minimum competition (for fruits) (Henson, 2007; Ranasinghe et al. 2012). The dry matter requirement for respiration (growth and maintenance respiration) of each organ can be determined using potential growth rate, biomass (dry weight) of the respective organs and the respiration coefficients. Although this information is available for some tree fruit crops (De Jong and Walton, 1989) and glasshouse grown crops (Marcelis and HofmanEijer, 1995; Marcelis et al. 2004), detailed quantitative information on above factors is so far lacking in coconut or any other palm species. Therefore, the objective of this study was to estimate and quantify the monthly dry matter requirement (sink strength) for growth (dry matter accumulation) and respiration of coconut fruits and vegetative organs of a palm.

\section{MATERIALS AND METHODS}

Forty healthy coconut palms (Cocos nucifera L., variety typica, Tall x Tall) selected from Walpita Research Station of Coconut Research Institute of Sri Lanka (CRISL) (Western Province, Wet Zone), two estates in Urapola (Western Province, Wet Zone) managed by Kurunegala Plantations Ltd and Makandura Research Station (Western Province, Wet Intermediate Zone) of the CRISL were used to estimate the dry matter requirement of fruits, leaves, stem and roots of palms. The plantations were of uniform age and density, and subjected to cultural practices recommended by the CRISL.

\section{Dry matter requirement for potential growth of fruits $\left(\mathrm{PGR}_{\mathrm{F}}\right)$, leaves $\left(\mathrm{PGR}_{\mathrm{L}}\right)$ and stem (PGR $)$}

Dry matter requirement for PGR from pollinated flower to mature fruit, was obtained by non-destructive measurements on 'potentially growing' fruits. Conditions for potential fruit growth were created by tagging fruits in each inflorescence and recording their growth rate under 'resource unlimited' conditions. To accomplish this condition, four fruits on newly pollinated youngest inflorescence (first), two fruits each on second and third inflorescences and one fruit each on other developing inflorescences were retained and all other developing flowers and fruits were removed (since some fruits of the first three inflorescences are prone to abort, more 
than one fruit was retained on the three youngest inflorescences). The developmental stages were approximately equally spaced in time. Data collection was done under highly favourable soil ( $\mathrm{S}_{2}$ Land suitability class) (Somasiri et al. 1994) and environmental conditions (no soil moisture stress, favourable temperature and solar radiation intensity). The fruits were assumed to grow with minimum competition under optimum environmental conditions to attain the potential size of each stage. Vertical circumference of the tagged fruits was measured at time $t_{1}$ and after one month at time $t_{2}$ and fruit dry matter content at $t_{1}$ and $t_{2}$ was estimated non-destructively by a fitted empirical relationship developed for the Tall coconut cultivar (Equation 1). The potential dry matter increase of fruit / month (potential growth rate, PGR) for each developing stage was calculated by the difference in estimated dry weight of fruits between months $\left(t_{2}-t_{1}\right)$.

For determining the dry matter requirement for $\mathrm{PGR}_{\mathrm{s}}$, vertical growth rate of stem under nonstressed conditions was monitored by marking a line just below the leaf crown. The increased volume of the stem over the period (considering that there is no detectable increase in stem circumference over time) and stem density were used to determine the $\mathrm{PGR}_{\mathrm{s}}$ per month. The number of new leaves emerged per month was nearly one for each palm. Therefore, the dry weight of leaves was used to determine the dry matter requirement for $\mathrm{PGR}_{\mathrm{L}}$. The potential growth rate of roots $\left(\mathrm{PGR}_{\mathrm{R}}\right)$ was not estimated in the present study.

$$
\mathrm{DM} \log =0.1486+\left(0.1472\left(\mathrm{~L}_{\text {vertical }}\right)\right)-\left(0.000741\left(\mathrm{~L}_{\text {vertical }}\right)^{2}\right) \quad \text { Equation } 1
$$

DM; dry matter content of the fruit $(\mathrm{g}), \mathrm{L}_{\text {vertical }}$; circumference of the fruit along the vertical axis (cm) (Ranasinghe et al., 2008) 
Dry matter requirement for growth respiration $\left(R_{g}\right)$, maintenance respiration $\left(R_{m}\right)$ and total (heterotrophic respiration $R_{a}$ ) of fruits, leaves, stem and roots

Dry matter requirement for respiration of a single fruit of all 14 developmental stages, leaves (approximately 28-30 fronds), stem and roots (only maintenance respiration) of a palm was estimated by a general model proposed by Penning de Vries et al. (1983) and Navarro et al. (2008).

$$
R_{a}=R_{g}+R_{m}=\alpha N P P+0.4 \beta B
$$

$R \quad$ - Respiration of organ $\left(\mathrm{g} \mathrm{C} \mathrm{m}^{-2}\right.$ day $\left.^{-1}\right)$, subscripts a, $\mathrm{g}$ and $\mathrm{m}$ denote total, growth and maintenance respiration, respectively

$\alpha \quad$ - Growth respiration coefficient $\left(\mathrm{g} \mathrm{C} \mathrm{gDM}^{-1}\right.$ ), (estimated from $0.67 \mathrm{~g} \mathrm{CO}_{2} \mathrm{~g} \mathrm{DM}^{-1}$ for fruits, $0.32 \mathrm{~g} \mathrm{CO}_{2} \mathrm{gDM}^{-1}$ for leaf and $0.25 \mathrm{~g} \mathrm{CO}_{2} \mathrm{gDM}^{-1}$ for stem (Navarro et al. 2008))

NPP - Net Primary Production of each organ $\left(\mathrm{g} \mathrm{DM} \mathrm{m}^{-2}\right.$ day $\left.^{-1}\right)$,

$0.4-\mathrm{C}$ : $\mathrm{CH} 2 \mathrm{O}$ molecular mass ratio

$\beta \quad$ - Maintenance respiration coefficient $\left(\mathrm{g} \mathrm{CH}_{2} \mathrm{O} \mathrm{g} \mathrm{DM}^{-1}\right.$ day $\left.^{-1}\right),(0.00184$ for fruits, 0.00245 for leaf, 0.0005 for stem and 0.0019 for roots (Navarro et al. 2008))

B - Biomass of the organ $\left(\mathrm{g} \mathrm{DM} \mathrm{m}^{-2}\right)$

The carbon requirement for $R_{g}, R_{m}$ and total respiration of a single fruit of each stage was determined using above equations and the carbon values were converted to dry mass by multiplying it by 2 (assuming $0.5 \mathrm{~g} \mathrm{C} \mathrm{g}_{\mathrm{DM}}{ }^{-1}$ (Matthews, 1993; Navarro et al. 2008)). Then, the dry matter requirement for growth (PGR), $R_{g}$ and $R_{m}$ of each bunch was calculated separately by multiplying the single fruit's requirement by the actual number of fruits remaining in a bunch. This was determined for continuous five months period from April to August 2009 using 16 palms. The total dry matter requirement of fruits / palm / month was estimated by summing up the requirement of all bunches on a palm. The variation of total dry matter requirement of fruits was studied in detail using fruit load data of 16 palms in the same field (Urapola, wet agro-climatic zone, $\mathrm{WL}_{3}$ ) for a period of two years (2009-2010).
PGR of stem and leaves was taken as the net primary productivity (NPP) of respective organs. Dry weight of stem was estimated by multiplying the volume of the stem with the mean density (The shape of the coconut stem was assumed to be cylindrical and tapering of the stem towards the top was not taken into account. The same approach has been taken by many researchers working on coconut) (Friend and Corley, 1994; Navarro et al. 2008)). Dry weight of total fronds per palm was estimated by using the actual dry weight of most mature frond and the crown leaf load (Navarro et al. 2008; Ranasinghe and Thimothias, 2012). The $R_{\mathrm{m}}$ of coconut root system was estimated using estimated root weight $(17 \%$ of above-ground weight for tree species) and maintenance respiration coefficients published by Navarro et al. (2008). Since the potential growth rate $\left(\mathrm{PGR}_{\mathrm{R}}\right)$ of roots were not estimated, the dry matter requirement for growth respiration $(\mathrm{Rg})$ was not estimated for roots in the present study. 
Analysis of data:

The data were analysed using General Linear Model (PROC GLM) of the SAS statistical package and (version 8.2).

\section{RESULTS AND DISCUSSION}

\section{Dry matter requirement of fruits}

Crown of coconut palms consists of about 14 fruit bunches of different developing stages. The time course of fruit weight increase was approximately sigmoidal with a substantial linear phase during which the greater part of the nut weight was attained (Fig 1). The period of rapid growth was from about sixth to tenth development stage after pollination. At harvest the weight of a coconut fruit was about $800 \mathrm{~g}$ (dry weight).

The DM requirement for potential growth (PGR) of a single fruit increased with age from development stage one to nine and the rate of increase was highest from stages five to six (39 $\mathrm{g}_{\text {fruit }}{ }^{-1}$ month $^{-1}$ ) (Fig 2a).

DM requirement for growth respiration $\left(\mathrm{R}_{\mathrm{g}}\right)$ reflected the same trend as PGR. The $\mathrm{DM}$ requirement for maintenance respiration

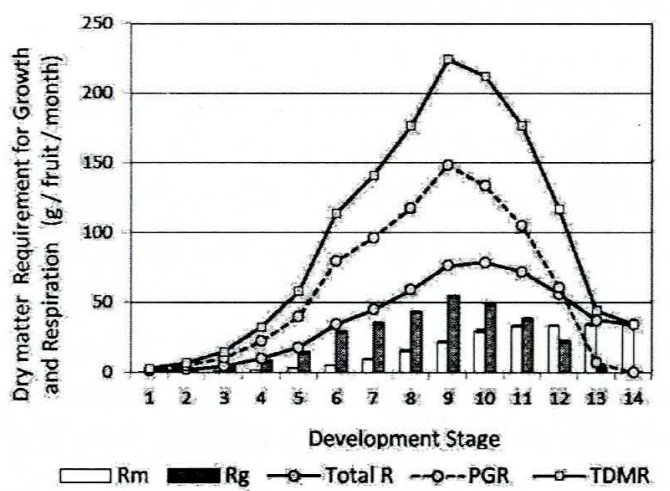

Fig 2: (a) Dry matter requirement for growth (PGR), respiration (maintenance $\left(R_{m}\right)$, growth $\left(R_{g}\right)$ and total (Total $R$ )) and total of growth and respiration (TDMR)
$\left(\mathrm{R}_{\mathrm{m}}\right)$ increased with maturity up to $11^{\text {th }}$ stage and remained constant. Consequently, the DM requirement for cumulative respiration (Total R) of a fruit was highest at ninth to tenth development stage and it was about $80 \mathrm{~g}$ fruit $^{-1}$ month $^{-1}$. The total dry matter requirement (TDMR) for growth and respiration of a fruit was also highest at ninth to tenth stage and it was about $225 \mathrm{~g} \mathrm{fruit}^{-1}$ month $^{-1}$ (Fig 2a). In young fruits, $\mathrm{DM}$ requirement for $\mathrm{R}_{\mathrm{m}}$ was only a small fraction $(<20 \%)$ of the total respiration, while from eighth to ninth stage, this fraction continuously increased with development stage (Fig 2b). DM requirement for $\mathrm{R}_{\mathrm{g}}$ showed the opposite trend.

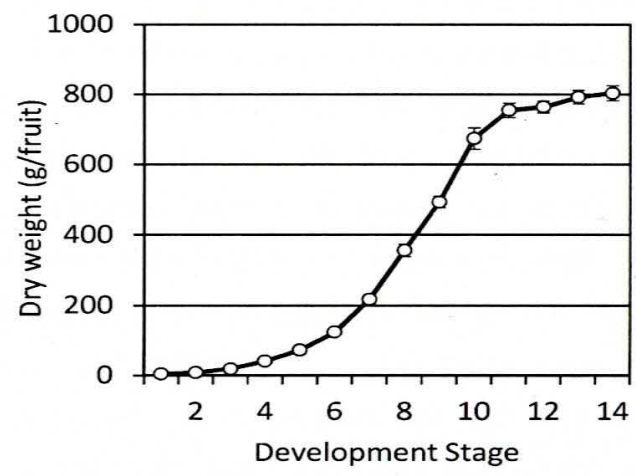

Fig 1: The pattern of dry weight increase ( $g$ /fruit) of coconut fruits as a function of development stage

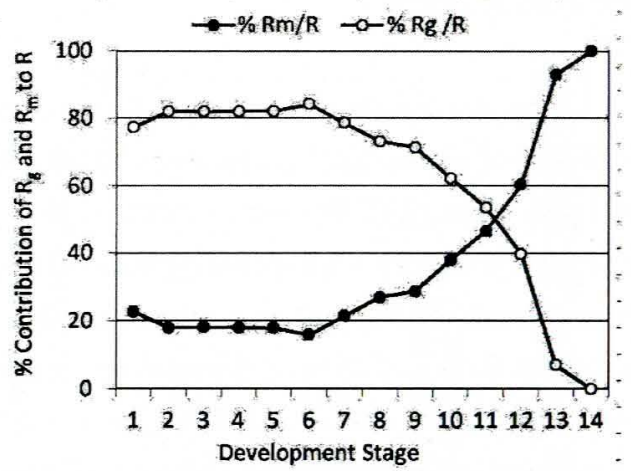

Fig 2: (b) percentage contribution of dry matter requirement for $R_{m}$ and $R_{g}$ to total $R$ of single fruits of 14 development stages.

Note: Development Stage 1 refers the fruit just after pollination and stage 14 refers the most mature fruit. The developmental stages are approximately equally spaced in time; approximately 27-29 days, thus there are 14 bunches present at a time on the palms. 
These variations in DM requirement with ontogeny of the fruit may be attributed to the physico-chemical changes that take place within fruit during the post- pollination phase (from fertilization to maturity). The fruit of coconut consists of four main components, namely, the husk, shell, liquid endosperm (nut water) and solid endosperm (kernel including lipids). The growth during the post-pollination phase, that is, from fertilization to maturity (10-11 month period), is mainly by cell enlargement which is associated with the accumulation of food reserves. The rapid growth phase of husk, shell and kernel extends from 3-7 months, 5-9 months and 6-10 months, respectively. It was evident that the commencement and termination of the growth of fruit components, husk, shell and endosperm, take place at different times. However, the growth of all three components overlapped during the period from fifth to ninth stage. Accumulation of dry matter in the solid endosperm (kernel) ceases after eleventh stage and with that the increase in dry weight of the whole fruit also ceases indicating that no assimilates are transported into the fruit after the full development of the endosperm (Jayasuriya and Perera, 1985).

Using the single fruit's requirements and fruit load of palms, total dry matter requirement of fruits/palm (TDMR) was estimated and it was approximately $8 \mathrm{~kg} / \mathrm{palm} /$ month (Fig 3). Fruit growth (PGR) and respiration accounted for about $60 \%$ and $40 \%$ of the total dry matter requirements, respectively. The two components of respiration required the same percentage of dry matter ( $20 \%$ each). There have been few attempts to quantify the actual dry matter requirement for growth and respiration of tree fruits under field conditions. For instance, Bazzaz et al. (1979) estimated that respiration accounted for $11-38 \%$ of the total carbohydrate requirement of fruits in 15 tree fruit species. Loescher et al. (1986) estimated that 16-23\% of the total carbohydrate requirement of a developing sweet cherry fruit is utilized in respiration. In a study on growth and respiration of peach fruits, respiration accounted for about $16 \%$ of the total carbohydrate requirement of fruits (Dejong and Walton, 1989).

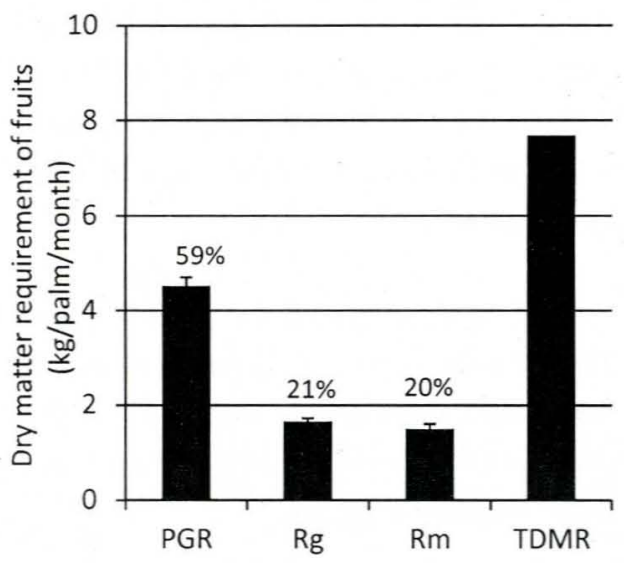

Fig 3: Dry matter requirement for growth (PGR), respiration $\left(R_{m}\right.$ and $R_{g}$ ) and total of growth and respiration (TDMR) of fruits /palm /month.

\section{Dry matter requirement of leaves}

The total dry matter requirement for growth and respiration of leaves was almost similar to that of fruits, however the contribution of different components to the total requirement was appreciably different from those of fruits (Fig 4a). For instance, about $60 \%$ of the total DM was required for maintenance respiration $\left(R_{m}\right)$ of the leaf crown whilst only $34 \%$ was required for growth of leaves (PGR). The percentage DM required for growth respiration $\left(\mathrm{R}_{\mathrm{g}}\right)$ of leaves was comparatively low $(6 \%)$. The total DM requirement of stem was significantly lower (about $3 \mathrm{~kg} / \mathrm{palm} / \mathrm{month}$ ) compared to 
other organs and almost $75 \%$ of that amount was required for maintenance respiration (Fig $4 b$ ). Since the stem showed the lowest growth rate, the DM requirement for Rg was lowest for the stem. The DM requirement for $\mathrm{R}_{\mathrm{m}}$ of root system was $2.15 \mathrm{~kg} / \mathrm{palm} /$ month and the DM requirement for growth (PGR) and $\mathrm{R}_{\mathrm{g}}$ of roots was not estimated in the present study.

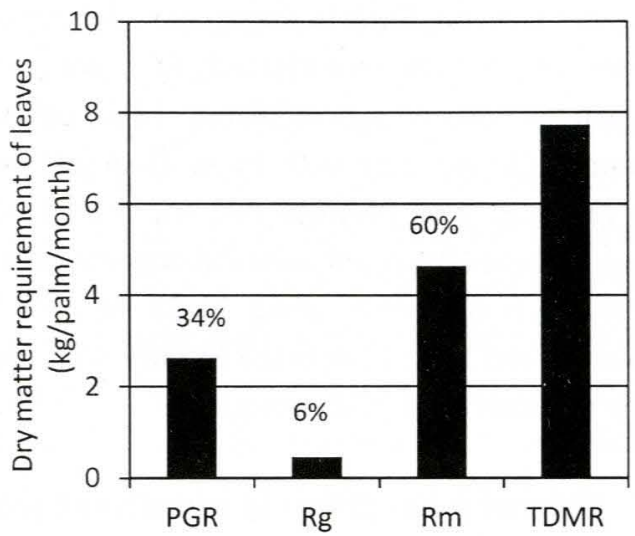

( a)

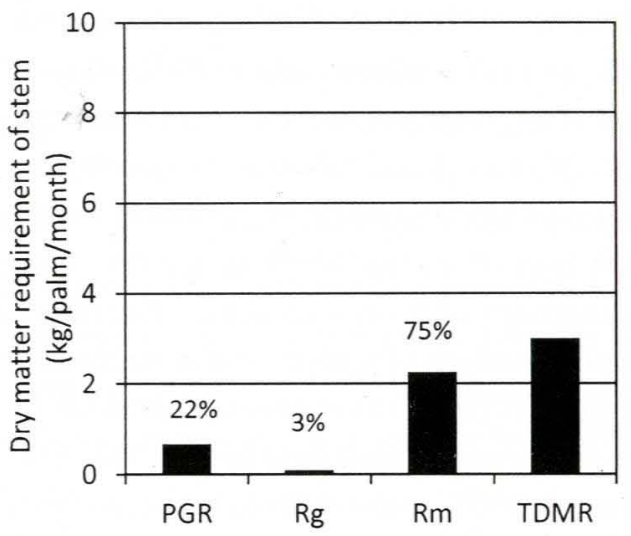

(b)

Fig 4: Dry matter requirement for growth (PGR), respiration (maintenance $\left(R_{m}\right)$, growth $\left(R_{g}\right)$ and total of growth and respiration (TDMR) of leaves (a) and stem (b).

\section{Contribution of total dry matter requirement of a palm by different organs and processes}

The total DM requirement of fruits and vegetative organs was about $21 \mathrm{~kg} / \mathrm{palm} / \mathrm{month}$ and nearly two-third of that was required for growth and respiration of vegetative organs (leaves, stem and roots, $63 \%$ ) and only one-third (37\%) of the total was required by fruits (Fig 5a). Similarly, the DM required for respiration (62\%) was nearly two third of the total requirement and only $38 \%$ was required for growth of organs (Fig $5 b$ ).

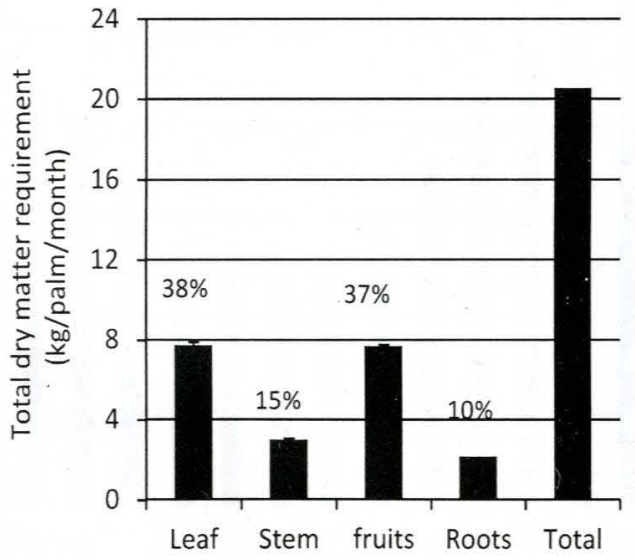

( a)

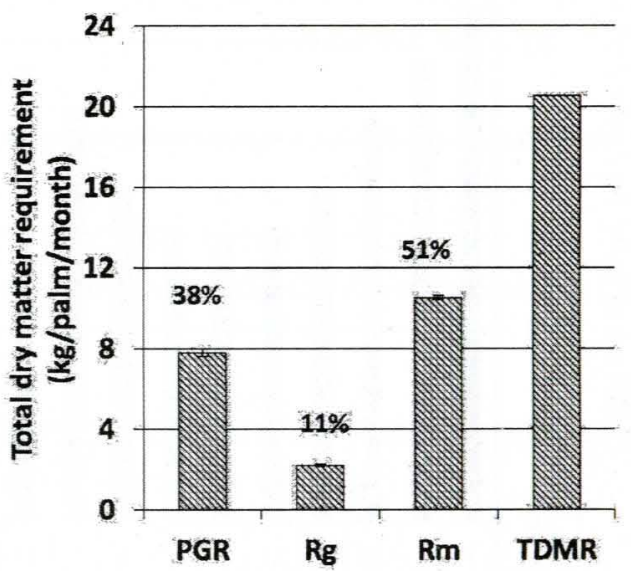

(b)

Fig 5: Total dry matter requirement of an adult coconut palm. (a) it's contribution by different organs and (b) its contribution by different processes (potential growth (PGR), maintenance respiration $\left(\mathrm{R}_{\mathrm{m}}\right)$, growth respiration $\left(\mathrm{R}_{\mathrm{g}}\right)$ and total of growth and respiration (TDMR) 
Coconut palm produces approximately one inflorescence every month and the fruit set in these inflorescences vary depending on the number of female flowers produced, source / sink ratio of the palm at inflorescence opening and climatic condition during final stages of flower development and fruit set (Ranasinghe et al. 2015 b). These variations in monthly fruit set contribute to significant variations in monthly fruit load of a palm affecting the dry matter requirement of fruits over time. Therefore, a detailed analysis of total dry matter requirement of fruits $\left(\mathrm{TDMR}_{\mathrm{F}}\right.$ ) over time was evaluated in the same experimental field for a period of two years. $\mathrm{TDMR}_{\mathrm{F}} /$ palm differed between months and years (Fig 6). Mean TDMR in $2009(9.4 \pm$ $0.23 \mathrm{~kg} \mathrm{palm}^{-1}$ month $^{-1}$ )

was significantly higher compared to that of 2010 $\left(8.2 \pm 0.23 \mathrm{~kg} \mathrm{palm}^{-1}\right.$ month $\left.^{-1}\right)$ and irrespective of the year, $\mathrm{TDMR}_{\mathrm{F}}$ of palms was highest during November to February and the values were significantly higher compared other months, except October. $\mathrm{TDMR}_{\mathrm{F}}$ was significantly low in June compared to those in September to March. These variations are mainly associated with low number of fruit set in February - March period (resulting low number of rapidly growing fruits in June-July) and high number of fruit set in May-August (resulting high number of rapidly growing fruits in September-January). However, the DM requirement of vegetative organs (a total of approximately $13 \mathrm{~kg} / \mathrm{palm} /$ month) did not vary with time. Therefore, it is reasonable to propose that the total DM requirement of an adult TallxTall coconut palm (25-30 yrs of age) is about $21-23 \mathrm{~kg} \mathrm{palm}^{-1}$ month $^{-1}$ and this is subjected to vary with the age of palms (size of the stem).

Coconut palms grown in intermediate and dry zones of Sri Lanka expose to supra optimal or high temperatures, especially during drought months, leading to reduction in the rate and duration of photosynthesis and consequently the dry matter production of palms. At the same time, since maintenance respiration coefficient is sensitive to high temperature, the DM requirement for maintenance respiration of palms can increase at high temperatures

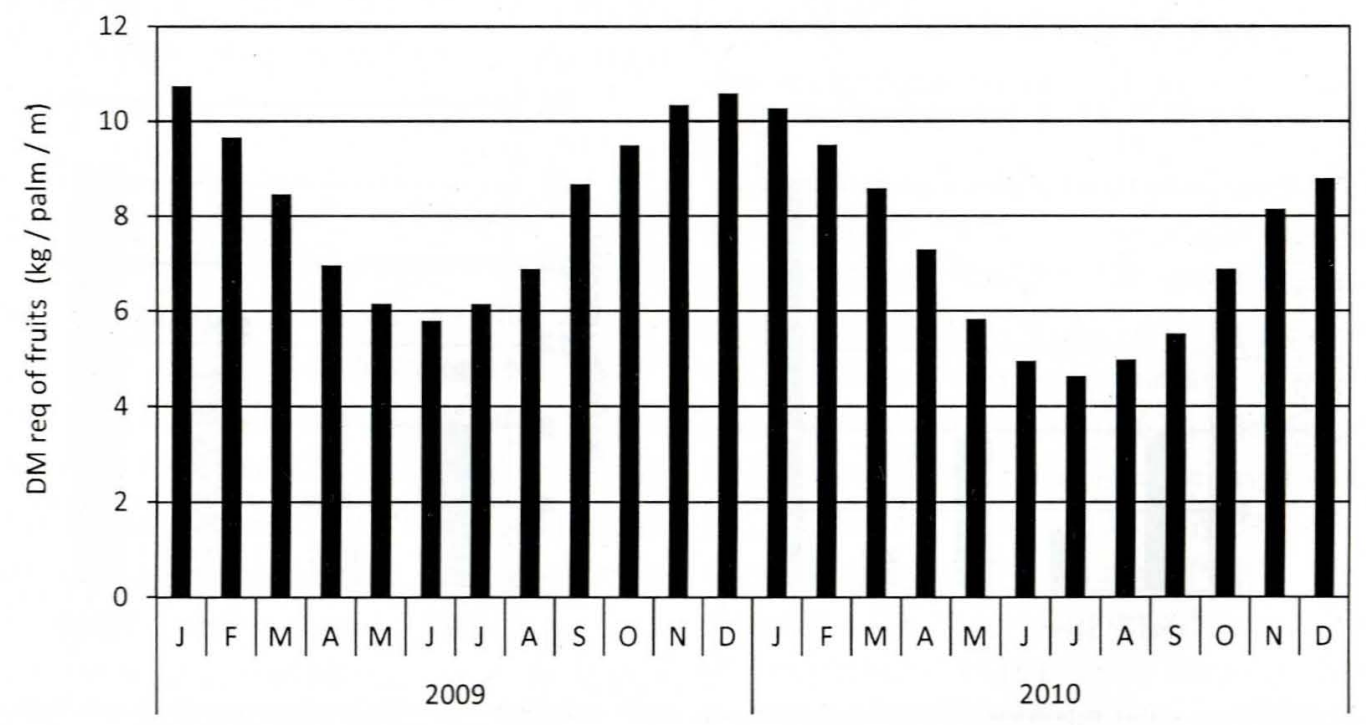

Fig 6: Variation in monthly total dry matter requirement of fruits $\left(\mathrm{TDMR}_{\mathrm{F}}\right)(\mathrm{kg} / \mathrm{palm} / \mathrm{month})$ from January 2009 through 
(Amthor, 1984). These imbalances can widen the gap between dry matter requirement and supply to developing fruits resulting abortion of young fruits and flowers. For example, although the mean total DM requirement of an adult TallxTall coconut palm (25-30 yrs of age) is about $21-23 \mathrm{~kg} \mathrm{palm}^{-1}$ month $^{-1}$ the mean total DM production of TallxTall cultivar was estimated as $17 \mathrm{~kg} / \mathrm{palm} /$ month under moderate climatic conditions in a recent study (Ranasinghe $e t$ al. 2015a). Under such conditions where the total dry matter supply is lower than the requirement, there is a high competition for assimilates between vegetative organs and developing fruits. However, in coconut (Mialet-Serra et al. 2008) and oil palm (Legros et al. 2009) there is a mechanism to adjust short-term source-sink imbalances by changing the light use efficiency and partly compensating transitory reserves in leaf petioles. In conclusion, the present study estimated the dry matter requirement of coconut palm by its different organs (fruits, leaves, stem and roots) and processes (growth and respiration). This quantitative information on assimilate requirement (sink strength) of different organs, specially the developing fruits, can be used in source/sink based crop forecasting models.

\section{REFERENCES}

Amthor J. S. (1984) The role of maintenance respiration in plant growth. Plant Cell and Environment 7, 561-569.

Bazzaz F. A., Carlson R. W. and Harper J. L. (1979) Contribution to reproductive effort by photosynthesis of flowers and fruits. Nature 279, 554-555.

Bertin N. (1995) Competition for assimilates and fruit position affect fruit set in indeterminate green house tomato. Annals of Botany 75, 55-65.

De Jong T. M. and Walton E. F. (1989) Carbohydrate requirement of peach fruit growth and respiration. Tree Physiology 5, 329-335.

Friend D. and Corley R.H.V. (1994). Measuring coconut palm dry matter production. Experimental Agriculture 30: 223-235.

Henson I.E. (2007) Modeling oil palm yield based on source and sink. Oil Palm Bulletin 54, 2751 .

Jayasuriya V.U.De.S. and Perera R.K.I.S. (1985). Growth, development and dry matter accumulation in the fruit of Cocos nucifera L. var. nana form pumila. $\operatorname{Cocos} 3,16-21$.

Legros, S., Mialet-Serra, I., Clement-Vidal A., Caliman, J P., Siregar, F. A., Fabre, D. and Dingkuhn, M. (2009a). Role of transitory carbon reserves during adjustment to climate variability and source-sink imbalances in oil palm (Elaeis guineensis). Tree Physiology 29: 1199-1211. 
Liyanage D.V. (1950). Sex life of the coconut palm. Ceylon Coconit Quarterly 11 (2), 33-35.

Loescher W., Roper T. and Keller J. (1986) Carbohydrate partitioning in sweet cherries. Proceedings of Washington State Horticulture Association 81, 240-248.

Marcelis L. F. M. (1996) Sink strength as a determinant of dry matter partitioning in the whole plant. Journal of Experimental Botany 47, 1281-1291.

Marcelis LF M and Heuvelink E (1999) Modelling fruit set, fruit growth and dry matter partitioning. Acta Horticulturae 499, 39-49.

Marcelis L. F. M., Heuvelink E., Hofman-Eijer L. R. B., Bakker J. D. and Xue L. B. (2004) Flower and fruit abortion in sweet pepper in relation to source and sink strength. Journal of Experimental Botany 55 (406) 2261-2268.

Marcelis L. F. M. and Hofman-Eijer L. R. B. (1995) Growth and maintenance respiratory costs of cucumber fruits as affected by temperature, and ontogeny and size of the fruits. Physiologia Plantarum 93, 484-492.

Matthews G. (1993) The carbon content of trees. Forestry Commission, Technical Paper 4, HMSO, London, 25p.

Mialet-Serra I., Clement-Vidal A., Roupsard O., Jourdan C. and Dingkuhn M. (2008) Wholeplant adjustments in coconut (Cocos nucifera) in response to sink-source imbalance. Tree Physiology 28: 1199-1209.

Nainanyake N. P. A. D., Ranasinghe C. S. and Tennakoon A. T. (2008) Effect of drip irrigation on canopy and soil temperature, leaf gas exchange, flowering and nut setting of mature coconut (Cocos nucifera L.). Journal of National Science Foundation Sri Lanka. 36 (1), 47-54.

Navarro M., Jourdan C., Sileye T., Braconnier S., Mialet-Serra I., Saint-Andre L., Dauzat J., Nouvellon Y., Epron D., Bonnefond J.M., Berbigier P., Rouziere A., Bouillet J.P. and Roupsard O. (2008). Fruit development, not GPP, drives seasonal variation in NPP in a tropical palm plantation. Tree Physiology 28, 1661-1674.

Penning de Vries F.W.T., Van Laar H.H. and Chardon M.C.M. (1983). Bioenergetics of growth of seeds, fruits and storage organs. Potential productivity of field crops under different environments. International Rice Research Institute, Manila, The Philippines.

Ranasinghe C.S., Kumarathunge, M.D.P, Jayaranjini S., Costa W.A.J.M. de (2015a). Photosynthetic irradiance with canopy strata in tall and dwarf $\mathrm{x}$ tall coconut cultivars (Cocos nucifera) scientia Horticulturae 189, 175 - 183. 
Ranasinghe C.S., Nainanayake N. P. A. D., Silva L. R. S. and Premasiri R. D. N. (2012) Quantifying the effect of climatic factors and competition for assimilates on survival rate of young nuts and its impact on yield fluctuation in coconut In: Proceedings of the fourth Symposium on Plantation Crop Research - Technological Innovations for sustainable plantation economy (Eds. L S K Hettiarachchi, I S B Abeysinghe), 20-21 September, Colombo, 265-282.

Ranasinghe C.S., Silva L.R.S., premasiri R.D.N. (2015b). Major determinants of fruit set and yield fluctuation in coconut (Cocos nucifera L), Journal of Naional Science Foundation 43(3), $253-264$.

Ranasinghe C.S. and Thimothias K.S.H. (2012) Estimation of carbon sequestration potential in coconut plantations under different growth conditions. Journal of National Science Foundation 40 (1):77-93.

Ranasinghe C.S, Waidyaratne K. P, Premasiri R. D. N. (2008). Report of the Plant Physiology Division, Annual Report of the Coconut Research Institute 2008, 201-202, Coconut Research Institute, Lunuwila.

Somasiri L.L.W., Nadarajah N., Amarasiri L. and Gunathilake H.A.J. (1994) Land suitability assessment of coconut growing areas in the coconut triangle (eds. C R Panabokke and Mahindapala R), The Coconut Research Institute, Sri Lanka. 